\title{
NR2B-Dependent Plasticity of Adult-Born Granule Cells is Necessary for Context Discrimination
}

\author{
Mazen A. Kheirbek, ${ }^{1,3}$ Lindsay Tannenholz, ${ }^{2,3}$ and René Hen ${ }^{1,2,3}$ \\ ${ }^{1}$ Departments of Neuroscience and Psychiatry and ${ }^{2}$ Department of Pharmacology, Columbia University, New York, New York 10032, and ${ }^{3}$ Division of \\ Integrative Neuroscience, The New York State Psychiatric Institute, New York, New York 10032
}

Adult-generated granule cells (GCs) in the dentate gyrus (DG) exhibit a period of heightened plasticity $4-6$ weeks postmitosis. However, the functional contribution of this critical window of plasticity to hippocampal neurogenesis and behavior remains unknown. Here, we show that deletion of NR2B-containing NMDA receptors from adult-born GCs impairs a neurogenesis-dependent form of LTP in the DG and reduces dendritic complexity of adult-born GCs, but does not impact their survival. Mice in which the NR2B-containing NMDA receptor was deleted from adult-born GCs did not differ from controls in baseline anxiety-like behavior or discrimination of very different contexts, but were impaired in discrimination of highly similar contexts. These results indicate that NR2B-dependent plasticity of adult-born GCs is necessary for fine contextual discrimination and is consistent with their proposed role in pattern separation.

\section{Introduction}

The mammalian dentate gyrus (DG) generates new neurons throughout life (Altman and Das, 1965) that functionally integrate into the local circuitry (Toni et al., 2008) and can account for up to $10 \%$ of the granule cell (GC) population (Imayoshi et al., 2008). Studies in which adult neurogenesis has been manipulated indicate that this process contributes significantly to behavior, and it is widely hypothesized that functional differences between immature and mature GCs underlie the unique role adult-born neurons play in DG function (Zhao et al., 2008; Sahay et al., 2011b).

The development of adult-born GCs is a highly plastic process that recapitulates a number of aspects of early development, including the preferential expression of NMDA receptors that contain the NR2B subunit (Cull-Candy and Leszkiewicz, 2004). There is an initial critical period from 1 to 3 weeks postmitosis, during which the survival and integration of adult-born GCs is dependent on both GABAergic and glutamatergic input (Ge et al., 2006; Zhao et al., 2008). In particular, survival of adult-born GCs near the end of this time window requires NMDA receptor activation (Tashiro et al., 2006). Accumulating evidence indicates the existence of a second critical window between 4 and 6 weeks of cell age, when adult-born GCs exhibit enhanced synaptic plas-

\footnotetext{
Received April 10, 2012; accepted May 5, 2012.

Author contributions: M.A.K. and R.H. designed research; M.A.K. and L.T. performed research; M.A.K. analyzed data; M.A.K. and R.H. wrote the paper.

This work was supported by NIMH Grant 1F32MH092101-01A1 and a National Alliance for Research on Schizophrenia and Depression (NARSAD) Young Investigator Award (M.A.K.); and NARSAD, the New York Stem Cell Initiative, NIH R01 MH068542, and Hope for Depression Research Foundation grants (R.H.). We thank Liam Drew and Benjamin Samuels for comments on the manuscript and members of the Hen laboratory for discussions on the project. We thank Hannah Moyner for providing the NR2 $B^{2 l o x}$ line; Alex Dranovsky for the NestinCreERT2 line; Helen Scharfman and Colin $0^{\prime}$ Carroll for assistance with electrophysiological recordings; Amy Radke, Daniel Costantini, and David Doobin for assistance with circuitry analysis and Christine Denny and Michael Drew for input on the NOR task.

Correspondence should be addressed to Dr. René Hen, 1051 Riverside Drive, Annex 767, Unit 87, New York, NY 10032. E-mail: rh95@columbia.edu.

DOI:10.1523/JNEUROSCI.1692-12.2012

Copyright $\odot 2012$ the authors $\quad 0270-6474 / 12 / 328696-07 \$ 15.00 / 0$
}

ticity and impact specific behavioral functions (Ge et al., 2007; Denny et al., 2012). Consistently, ablation of neurogenesis prevents the induction of LTP evoked by medial perforant path (MPP) stimulation in the DG of slices with intact GABAergic transmission (ACSF-LTP), suggesting that this synaptic potentiation reflects a selective effect on adult-born GCs (Snyder et al., 2001; Saxe et al., 2006). This form of LTP is blocked by ifenprodil or Ro25-6981, NR2B subtype-specific antagonists, demonstrating that this NMDA subunit is essential for increased synaptic plasticity (Snyder et al., 2001; Ge et al., 2007). Together, these data indicate that during this 4-6 week window, adult-born GCs are hyperplastic and may as a result make unique contributions to DG circuits and hippocampal function. However, whether this period of enhanced plasticity influences the integration of young neurons into hippocampal circuitry, or influences behavior by other means, remains unknown. To test this, we selectively deleted the NR2B subunit of the NMDA receptor from adult-born GCs to study the functional impact of heightened synaptic plasticity and the requirement of NR2B for adult-born GC survival.

\section{Materials and Methods}

Mice

NestinCreERT2 and NR2B f/f mice were generated as previously described (von Engelhardt et al., 2008; Dranovsky et al., 2011). Experimental male mice were generated by breeding NestinCreERT2;NR2Bf/f with $N R 2 B^{f / f}$ mice. For labeling adult-born GCs, NestinCreERT2;NR2B ${ }^{f /+}$; ROSA26 $6^{\text {stopEYFP/ fstopEYFP }}$ were bred with NestinCreERT2;NR2B $B^{f /+}$ to generate NestinCreERT2;NR2B ${ }^{f / f} ;$ ROSA26 $6^{\text {stopEYFP/+ }}$ and NestinCreERT2;NR2B ${ }^{+/+}$; ROSA26 $6^{\text {stopEYFP /+ }}$ controls. Mice (8- to 10-weeks-old) were injected with 3 mg of tamoxifen [TMX; vehicle (VEH) solution of corn oil/10\% ethanol] intraperitoneally once per day for 5 consecutive days. Previous work with this strain revealed that a brief pulse of TMX does not affect hippocampusdependent behavior 6 weeks later (Sahay et al., 2011a). All experiments were approved by the Institutional Animal Care and Use Committee at Columbia University and the New York State Psychiatric Institute. 


\section{Immunohistochemistry}

For survival experiments, $48 \mathrm{~h}$ after the last TMX or VEH injection, BrdU was injected intraperitoneally $(150 \mathrm{mg} / \mathrm{kg})$. For all experiments, mice were perfused ( $4 \%$ paraformaldehyde), brains postfixed, cryoprotected, and sections $(35 \mu \mathrm{m})$ of the entire DG were labeled for BrdU, GFAP, NeuN, doublecortin (DCX), Ki67, or GFP [rat-anti-BrdU, 1:100 (Serotec); rabbit-anti-GFAP, 1:1500 (DAKO); mouse-anti-NeuN, 1:500 (Millipore Bioscience Research Reagents); goat-anti-DCX, 1:500 (Santa Cruz Bioscience); rabbit-anti-Ki67, 1:100 (Vector)], as previously described (Sahay et al., 2011a). Experimenters blind to treatment counted (at 20×) BrdU, DCX, and Ki67 cells in every sixth section throughout the DG, and DCX cells exhibiting tertiary dendrites were counted. For colabeling of BrdU/NeuN/GFAP, confocal scans (FluoView1000; Olympus) at $40 \times$ were taken of $60 \mathrm{BrdU}$ cells/treatment across the anteroposterior (AP) axis of the DG. For enhanced yellow fluorescent protein (EYFP)/DCX counts, $120 \mathrm{DCX}+$ cells were imaged across the AP axis of the DG to determine colabeling with EYFP, excluding type- 1 cells determined by their radial-glia morphology. Sholl analysis was conducted as previously described (Sahay et al., 2011a) and analyzed with the ImageJ Sholl Analysis plug-in (http://www-biology.ucsd.edu/labs/ghosh/software/).

\section{Slice electrophysiology}

Transverse hippocampal slices $(400 \mu \mathrm{m})$ were incubated in an interface chamber at $32^{\circ} \mathrm{C}$ and perfused with oxygenated ACSF (in mM: $11 \mathrm{NaCl}$, $2.5 \mathrm{KCl}, 1.3 \mathrm{MgSO}_{4}, 2.5 \mathrm{CaCl}_{2}, 26.2 \mathrm{NaHCO}_{3}, 1 \mathrm{NaH}_{2} \mathrm{PO}_{4}, 11$ glucose). Slices equilibrated for $2 \mathrm{~h}$ before a bipolar stimulating electrode was placed in the MPP and evoked field potentials were recorded in the molecular layer using a glass capillary microelectrode (1-3 M $\Omega$ ) filled with ACSF. Isolation of the MPP was confirmed by assessing pairedpulse depression of the MPP/DG synaptic connection at $50 \mathrm{~ms}$, which generated the highest level of depression (McNaughton, 1980). Inputoutput curves were obtained after $10 \mathrm{~min}$ of stable recordings. The stimulation intensity that produced one-third of the maximal response was used for the test pulses and tetanus. After $15 \mathrm{~min}$ of stable baseline (once every $20 \mathrm{~s}$ ), LTP was induced with four trains of $1 \mathrm{~s}$ each, $100 \mathrm{~Hz}$ within the train, repeated every $15 \mathrm{~s}$. Responses were recorded every $20 \mathrm{~s}$ for 60 min after LTP induction. The same protocol was used to elicit and record LTP of mature GCs except that $10 \mu \mathrm{m}$ bicuculline was added to the ACSF to block $\mathrm{GABA}_{\mathrm{A}}$-receptor-mediated inhibition.

\section{Behavioral experiments}

All behavioral experiments were conduced in male mice 14-16 weeks of age. For each test, time after TMX or VEH injection is noted in the figures or text.

Open field. Mice were placed in an acrylic open-field chamber $40 \mathrm{~cm}$ long $\times 40 \mathrm{~cm}$ wide $\times 37 \mathrm{~cm}$ high with illumination set to $16-20$ lux (low lux) or 600 lux (high lux). Data were collected in 5 min bins during 60 min trials and analyzed for total distance traveled as well as time and distance traveled in center.

Forced-swim test, novelty suppressed feeding, and elevated plus maze. Forced-swim test (FST), novelty suppressed feeding (NSF), and elevated plus maze (EPM) were conducted as previously described (Dulawa et al., 2004; David et al., 2009; Sahay et al., 2011a).

Novel object recognition. Naive mice were placed in a storage container $(45 \times 30 \times 30 \mathrm{~cm})$ with woodchip bedding, and videotaped from above at a light intensity of 16-20 lux. Two objects were placed at either end of the arena (a slide box, a clear funnel, or a white ceramic shoe; randomized presentation). Mice explored two objects for four trials of $5 \mathrm{~min}$, with a 3 min intertrial interval (during which the box would be wiped clean and the bedding changed), then one object was replaced with a novel object. An experimenter blind to the treatment condition analyzed videotapes, and total approaches, investigation time, and grid crossings were measured for each of the trials.

Fear conditioning. Conditioning took place in Coulbourn fear conditioning boxes that contained one clear Plexiglas wall, three aluminum walls, and a stainless steel grid floor. In the one-trial contextual fear conditioning, the training context (A) included a house light and fan, and anise scent was placed under the grid floor. After $180 \mathrm{~s}$, mice received single $2 \mathrm{~s}$ foot shock of $0.75 \mathrm{~mA}$. Mice were taken out $15 \mathrm{~s}$ after termina- tion of the foot shock and returned to their home cage. The box was cleaned with Sanicloths (Professional Disposals International) between runs. Digital video cameras recorded the session; FreezeFrame and FreezeView software (Actimetrics) were used for recording and analyzing freezing behavior. For the dissimilar context, $\mathrm{C}$, the grid floor was covered with a plastic panel and cage bedding. The chamber walls were covered and made circular using plastic inserts, the house fan and lights were turned off, and a mild lemon scent was placed below the grid floor. The chamber door was left ajar during testing. Ethanol (70\%) was used to clean the chamber between runs.

Naive mice were used for contextual fear discrimination. The training context, $\mathrm{A}$, was the same as used above for one-trial fear conditioning. The dissimilar context, $\mathrm{C}$, was as described above, and the similar (noshock) context, B, shared many features of the training context, including an exposed stainless steel grid floor, but differed in that two plastic inserts were used to cover the walls and make them circular, the house fan and lights were turned off, and the chamber door was left ajar during testing. A lemon scent was used as an olfactory cue, and $70 \%$ ethanol was used to clean the grids between runs. Mice were brought into the testing room in transport buckets by the same experimenter who had handled the mice for the training context. After $2 \mathrm{~h}$, mice were placed in the similar context, in which they were left for $180 \mathrm{~s}$ and were never shocked. Measurement of the freezing levels in both the training context ( 3 min preshock) and the similar context ( $3 \mathrm{~min}$ ) each day allowed the assessment of freezing in the two contexts. The order of presentation of contexts was randomized across days.

\section{Results}

Mice in which exon 9 of the $N R 2 B$ gene was flanked by two loxP sites (NR2B $\left.{ }^{2 l o x}\right)$ (von Engelhardt et al., 2008) were bred with NestinCreER $R^{T 2}$ mice in which the TMX regulated Crerecombinase $\left(\mathrm{CreER}^{\mathrm{T} 2}\right)$ is expressed under the control of a nestin promoter fragment (Dranovsky et al., 2011). TMX injection in adult mice excises sequences between the loxP sites selectively in neural stem cells and transit-amplifying progenitors to generate adult-born GCs lacking NR2B $\left(i N R 2 B^{\text {Nes }}\right)$. Using EYFP as a surrogate for NR2B recombination and marker for adult-born GCs (Fig. $1 A, B$ ), we found that $71.9 \pm 7.2 \%$ of DCX-positive neurons expressed EYFP 6 weeks after TMX induction.

We next assessed whether NR2B is required for young GC survival. In animals expressing the EYFP reporter, young GC numbers did not significantly differ between $N R 2 B^{f / f}$ and $N R 2 B^{+/+}$littermates (unpaired $t$ test, $n=3$ /genotype, $t_{4}=0.79$, $p=0.49$; Fig. $1 C$ ). In addition, BrdU pulse-chase experiments indicated that NR2B deletion did not affect survival of 2-, 4-, 6-, or 8-week-old neurons, as no difference was seen in number of BrdU-positive cells or phenotype of cells born after NR2B deletion $\left(n=3-7 /\right.$ treatment, unpaired $t$ test, 2 weeks: $t_{4}=1.3, p=$ 0.3 ; 4 weeks: $t_{4}=0.6, p=0.6 ; 6$ weeks: $t_{7}=-1.4, p=0.2 ; 8$ weeks: $t_{11}=-1.7, p=0.13$; percentage of BrdU/NeuN: $t_{4}=1.87$, $p=0.14$; Fig. $1 E, F)$. There was also no difference between $i N R 2 B^{N e s}$ and controls in progenitor proliferation as measured by Ki67 + cells $\left(n=5 \mathrm{TMX}, 4 \mathrm{VEH}\right.$, unpaired $t$ test, $t_{7}=-1.5, p=$ 0.18 ; Fig. $1 E$ ) or in generation of immature DCX-positive neurons $\left(n=5 \mathrm{TMX}, 4 \mathrm{VEH}\right.$, unpaired $t$ test, $t_{7}=-0.7, p=0.52$; Fig. $1 F, I)$. We next assessed dendritic complexity of adult-born GCs lacking NR2B. Although within the DCX population, the number of cells that exhibited tertiary dendrites did not differ between TMX and VEH treatment ( $n=5 \mathrm{TMX}, 4 \mathrm{VEH}$, unpaired $t$ test, $t_{7}=-0.8, p=0.44$; Fig. $1 \mathrm{~J}$ ), Sholl analysis on the dendrites of EYFP+ neurons from $N R 2 B^{f / f}$ and $N R 2 B^{+/+}$littermates 6 weeks after TMX injection revealed a decrease in dendritic complexity after deletion of NR2B ( $n=12-15$ cells $/ 3$ mice/treatment, repeated-measures ANOVA, genotype $\times$ distance interaction $F_{(28,700)}=1.5, p=0.03$; Fig. $\left.1 K\right)$. 
A
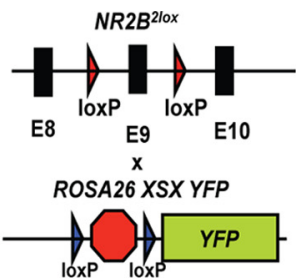

B

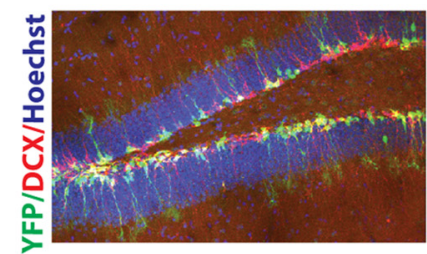

$\mathrm{NCreER}{ }^{\mathrm{T}} / \mathrm{NR} 2 \mathrm{~b}^{+/+}$ Rosa26yipl+

D

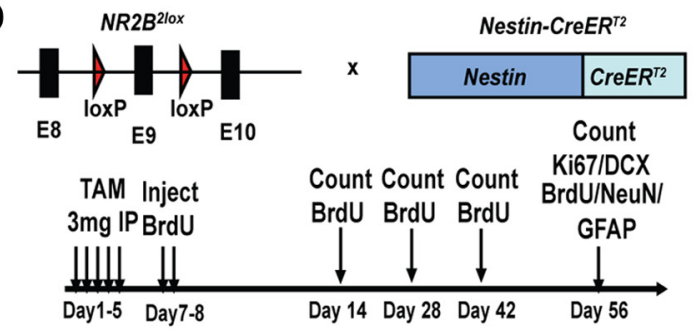

Nestin-CreER ${ }^{\text {T2 }}$
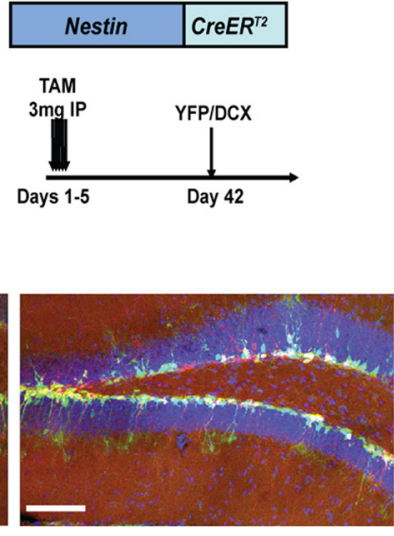

$\mathrm{NCreER}{ }^{\mathrm{T}} / \mathrm{NR} 2 b^{+}$ Rosa26 $6^{\text {ypl } /+}$

E
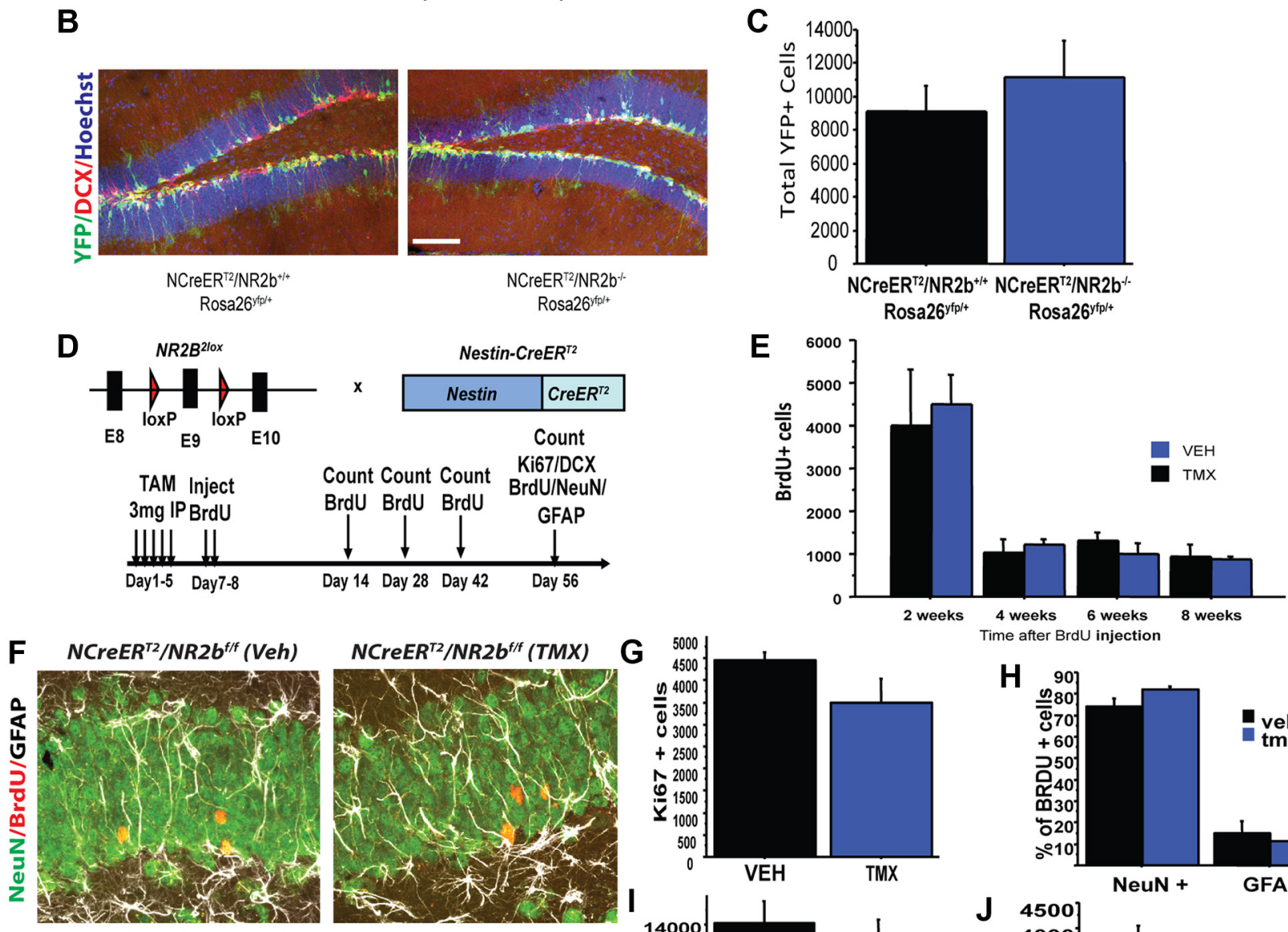

NCreER $R^{T 2} / N R 2 b^{f / f}(T M X)$
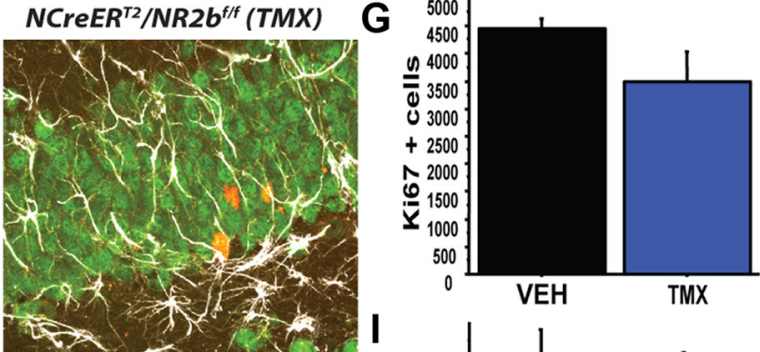

H
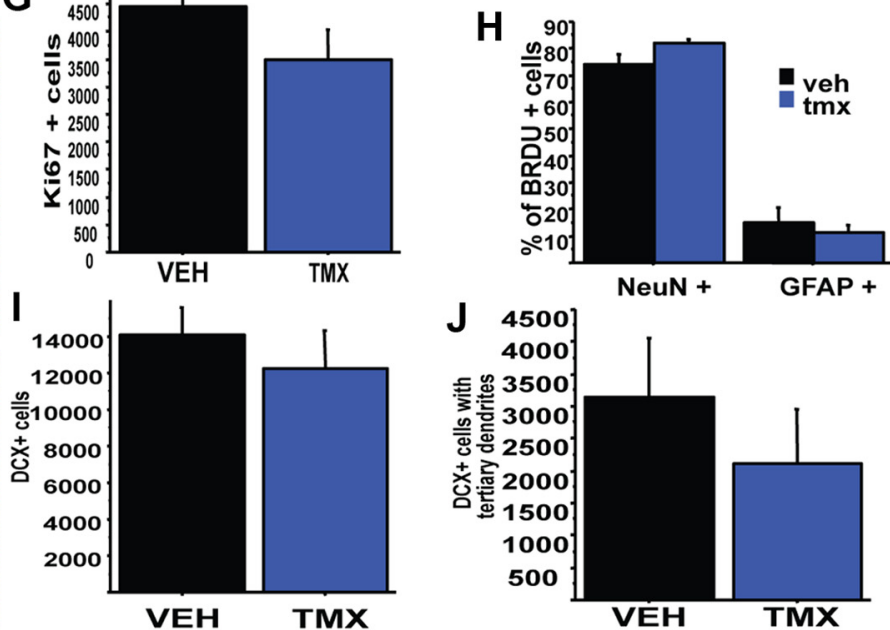

J 450

NeuN +

GFAP +
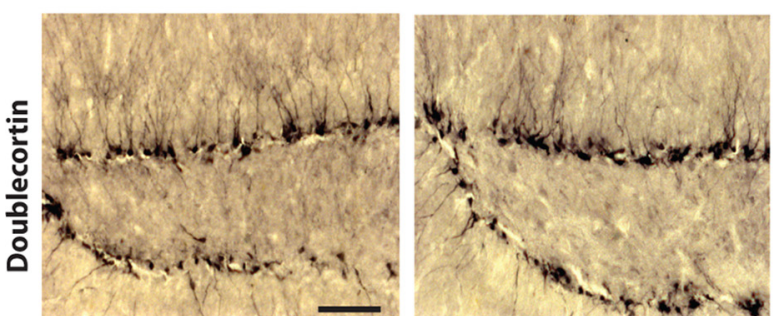

K NCreER ${ }^{\mathrm{T}} / \mathrm{NR}^{2} \mathrm{~b}^{+/+}$

NCreER ${ }^{\mathrm{T}} / \mathrm{NR}^{2} \mathrm{~b}^{-1}$
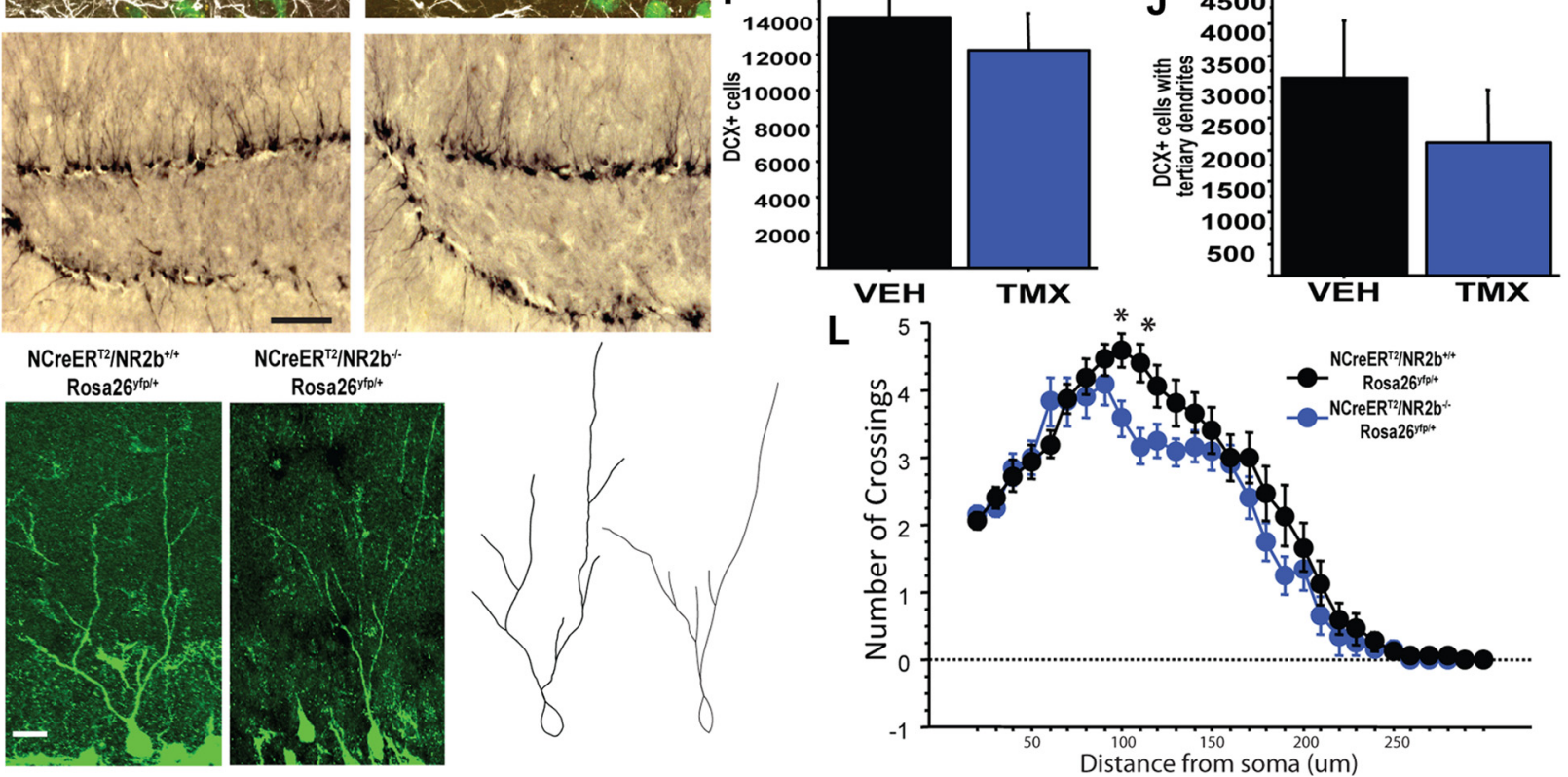

Figure 1. Deletion of NR2B in adult-born GCs does not affect neurogenesis in the DG. $\boldsymbol{A}, \boldsymbol{B}$, Three-mouse design using an inducible reporter, EYFP, to measure GC survival and TMX-induced recombination $(\boldsymbol{A})$ with representative images of YFP and DCX expression 6 weeks after TMX injection (B). Scale bar, $100 \mu \mathrm{m}$. $\boldsymbol{C}$, Total number of adult-born GCs did not (Figure legend continues.) 

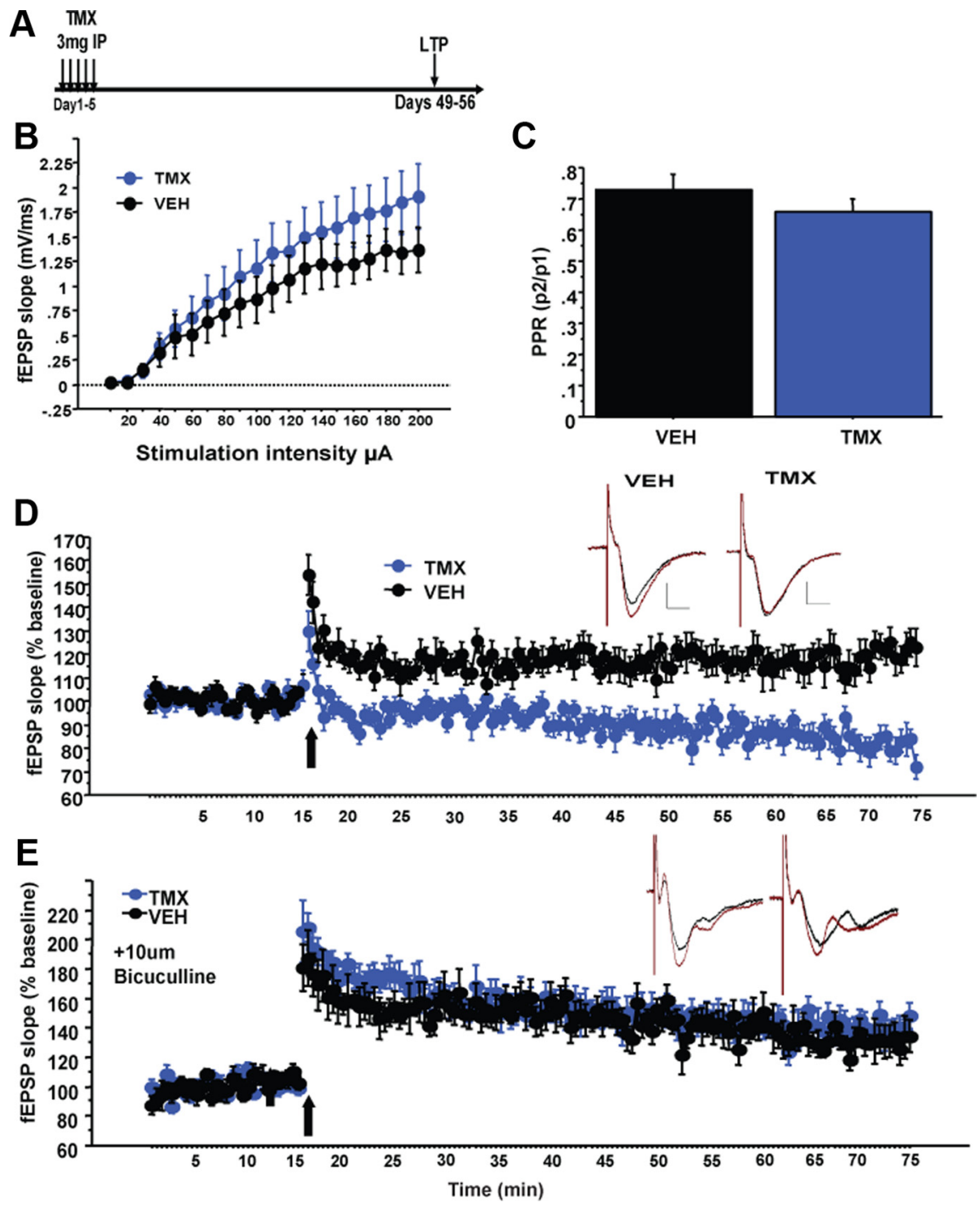

Figure 2. Impaired ACSF-LTP in the DG of iNR2B ${ }^{\text {Nes }}$ mice. $A$, Experimental timeline for electrophysiology experiments. $B, C$, No differences in input- output relationship ( $\boldsymbol{B}$ ) or paired-pulse depression ( $\boldsymbol{C}$; paired-pulse ratio (PPR), $50 \mathrm{~ms}$ interstimulus interval) of MPP inputs to the DG after deletion of NR2B. D, Significantly impaired ACSF-LTP in slices from iNR2B ${ }^{\text {Nes }}$ mice compared with controls. Inset, Representative average traces before and after HFS. Scale bars: verticle, $0.5 \mathrm{mV}$; horizontal, $5 \mathrm{~ms}$. $\boldsymbol{E}$, No difference in magnitude of LTP in slices in the presence of $10 \mu \mathrm{m}$ bicuculline. Data are mean $\pm \mathrm{SEM}$.

To determine the consequence of NR2B deletion in adult-born neurons on synaptic plasticity in the DG, we measured neurogenesis-dependent ACSF-LTP in slices taken 6-7 weeks after VEH or TMX treatment. Deletion of NR2B did not disrupt the input-output relationship $(n=12$ slices/genotype, repeated-measures ANOVA, treatment effect: $F_{(1,22)}=0.85, p=$ 0.37 , treatment $\times$ intensity interaction: $F_{(19,418)}=1.1, p=0.38$; Fig. 2B) or paired-pulse depression of fEPSPs evoked by MPP

(Figure legend continued.) differ between NR2B-deficient and WT littermate controls 6 weeks after TMX injection, as measured by total numbers of EYFP cells. $D$, Genetic and experimental timeline for neurogenesis measurement. $\boldsymbol{E}$, No effect on cell survival as measured by BrdU number at specified times postinjection. $\boldsymbol{F}$, Representative images for BrdU (green, NeuN; red, BrdU; white, GFAP) and DCX experiments. Scale bar: top, $30 \mu \mathrm{m}$; bottom, $100 \mu \mathrm{m}$. G, № effect of treatment on total Ki67-immunoreactive cells. $\boldsymbol{H}$, No significant difference in phenotype of BrdU cells 8 weeks after induction. $I, J$, No significant difference in total number of DCX cells or DCX + cells with tertiary dendrites. $\boldsymbol{K}, \boldsymbol{L}$, Sholl analysis revealed a decrease in dendritic complexity in adult-born GCs lacking NR2B. $K$, Representative images and tracings. Scale bar, 20 $\mu \mathrm{m}$. Data are mean \pm SEM. stimulation $\left(t_{21}=1.08, p=0.29\right.$; Fig. $\left.2 C\right)$. However, ACSF-LTP induction by highfrequency stimulation (four $1 \mathrm{~s}, 100 \mathrm{~Hz}$ trains every $15 \mathrm{~s}$ ) was absent in $i N R 2 B^{\text {Nes }}$ slices (repeated-measures ANOVA, last 10 min treatment effect: $F_{(1,22)}=25.5, p<$ 0.001 ; Fig. $2 D$ ). In contrast, LTP obtained in the presence of the $\mathrm{GABA}_{\mathrm{A}}$ receptor antagonist bicuculline did not differ between groups $(n=4 \mathrm{VEH}, 7$ TMX, repeatedmeasures ANOVA, last $10 \mathrm{~min}$ treatment effect: $F_{(1,9)}=0.9, p=0.37$; Fig. $\left.2 E\right)$. These results suggest that the mature GCs exhibit normal LTP and that the deficit in ACSFLTP is due to loss of NR2B in the immature neuron population. These $i N R 2 B^{N e s}$ mice therefore provide a model to test the contribution of the enhanced synaptic plasticity of immature neurons to behavior.

We next tested $i N R 2 B^{\text {Nes }}$ mice in a number of depression/anxiety-related behavioral assays. In neither low nor high lux open-field testing did the $i N R 2 B^{\text {Nes }}$ mice differ from controls in locomotor activity, habituation, or percentage of time in center, but in the low lux condition they showed a trend toward less distance traveled in the center of the arena (low lux: $n=13 /$ treatment, total distance traveled: treatment effect: unpaired $t$ test, $t_{24}=0.15, p=0.9$; treatment $\times$ time interaction: $F_{(11,264)}=1.19, p=0.29$; percentage time in center: $t_{24}=-1.5, p=$ 0.15 ; percentage center distance: $t_{24}=$ $-2.03, p=0.05$; high lux: total distance traveled: treatment effect: $t_{10}=0.14, p=$ 0.9 ; treatment $\times$ time interaction: $F_{(10,110)}$ $=0.89, p=0.55$; percentage time in center: treatment effect: $t_{10}=-0.5, p=0.63$; percentage center distance: $t_{10}=-0.7$, $p=0.9$; Fig. $3 A-F)$. In addition, as seen in irradiated animals at baseline (Santarelli et al., 2003; David et al., 2009), iNR2B ${ }^{\text {Nes }}$ mice did not significantly differ from control mice in immobility time in the FST, in open arm time in the EPM, or latency to feed in the NSF $(n=6 /$ treatment, FST: treatment effect: $F_{(1,10)}=0.01, p=0.9$; treatment $\times$ time interaction: $F_{(5,50)}=0.6, p=0.7$; EPM: $t_{10}=1.9, p=0.08$; NSF: $n=12-13 /$ treatment, Kaplan-Meier Survival analysis, Mantel-Cox logrank test, $p=0.6$, unpaired $t$ test, $t_{23}=1.2, p=0.26$; Fig. $3 G-I$ ).

Recently, arresting adult neurogenesis has been shown to impact novelty exploration (Jessberger et al., 2009; Denny et al., 2012). To test whether impaired DG plasticity in $i N R 2 B^{N e s}$ mice influences novelty exploration, mice explored two objects for 5 min for four consecutive trials, then one object was replaced with a novel object and number of approaches to the novel object were measured (Fig. 4A). iNR2 $B^{\text {Nes }}$ mice explored the objects and the arena less than control mice during early training trials, yet they habituated to arena and objects similar to control mice $(n=$ 12/treatment, total object approaches: repeated-measures ANOVA genotype effect: $F_{(1,22)}=6.03, p=0.02$, genotype $\times$ trial interaction: $F_{(3,66)}=0.34, p=0.8$; arena grid crossings: ANOVA genotype effect: $F_{(1,22)}=6.23, p=0.021$; genotype $\times$ trial inter- 

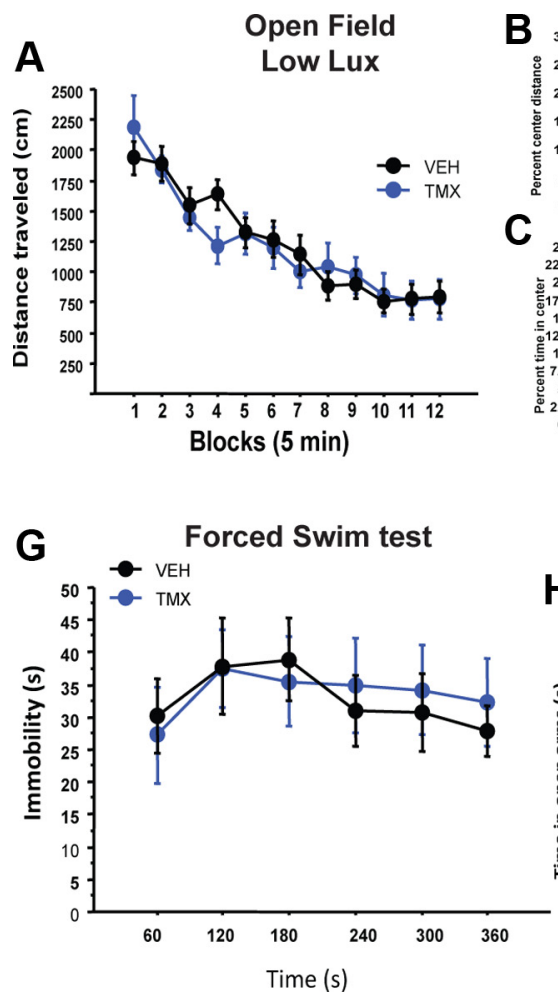
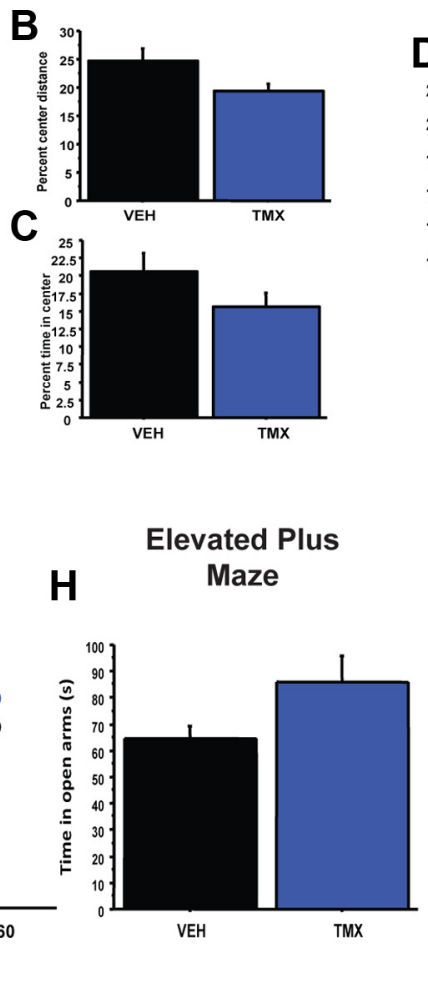
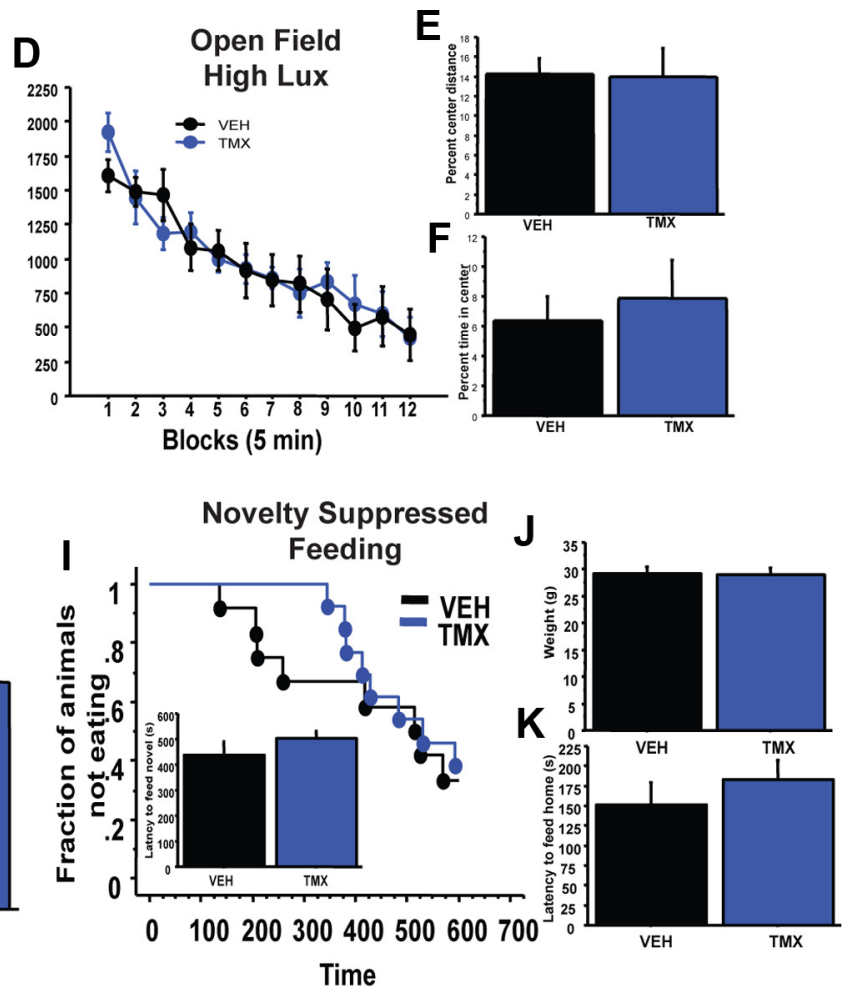

Figure 3. $i N R 2 B^{N e s}$ mice in depression/anxiety-related behavioral assays. $\boldsymbol{A}-\boldsymbol{F}$, Open-field test under low and high lux conditions with total distance traveled $(\boldsymbol{A}, \boldsymbol{D})$, percentage center distance $(\boldsymbol{B}, \boldsymbol{E})$, and percentage center time $(\boldsymbol{C}, \boldsymbol{F}) . \mathbf{G}$, Forced-swim test. $\boldsymbol{H}$, Elevated plus maze. I, Novelty suppressed feeding task. $\boldsymbol{J}, \boldsymbol{K}$, iNR2 $B^{\text {Nes }}$ mice did not differ in weight or latency to feed in their home cage. iNR2 $B^{\text {Nes }}$ mice did not differ from controls in FST, EPM, or NSF. Data are mean \pm SEM.

action: $F_{(4,88)}=0.75, p=0.56$; Fig. $\left.4 B\right)$. When the familiar object was replaced with a novel object, $i N R 2 B^{\text {Nes }}$ did not discriminate between the two objects [repeated-measures ANOVA, genotype effect: $F_{(1,22)}=5.6, p=0.03$; genotype $\times$ object interaction: $F_{(2,22)}=12.2, p=0.002$; discrimination ratio (novel - familiar/ total): $\mathrm{VEH}=0.495 \pm 0.08, \mathrm{TMX}=0.023 \pm 0.13, p=0.005$; Fig. $4 C)$, further highlighting a deficit in exploration in $i N R 2 B^{\text {Nes }}$ mice.

We next tested $i N R 2 B^{N e s}$ in a one-trial contextual fear conditioning. $i N R 2 B^{N e s}$ mice did not differ from control mice in time spent freezing in the shock context " $\mathrm{A}$ " $24 \mathrm{~h}$ after training, or in a significantly different context presented $48 \mathrm{~h}$ after training, suggesting that rapid encoding of contextual information was unaffected $(n=25 \mathrm{VEH}, 24 \mathrm{TMX}$, repeated-measures ANOVA, treatment effect: $F_{(1,47)}=0.8, p=0.4$; treatment $\times$ training effect: $F_{(1,47)}=0.54, p=0.46$; Fig. $4 E$ ). To assess contextual discrimination, $i N R 2 B^{N e s}$ mice were tested in two fear discrimination tasks that required mice to either distinguish between two very different contexts (Fig. $4 F, G$ ) or two highly similar contexts (Fig. $4 H, I$ ). Both groups of mice could efficiently discriminate between the two different contexts $(n=6$ /group, treatment effect: $F_{(1,20)}=0.9, p=0.4$; context effect: $F_{(1,20)}=40.8, p<0.001$; genotype $\times$ day $\times$ context interaction: $F_{(2,40)}=0.04, p=0.96$; Fig. $4 G$ ). Yet, when tested to discriminate between two highly similar contexts, freezing scores revealed that $i N R 2 B^{N e s}$ mice took longer to learn the task, suggesting impaired fine discrimination in $i N R 2 B^{N e s}$ mice $(n=15-17 /$ treatment, repeated-measures ANOVA, day $\times$ genotype $\times$ context interaction: $F_{(7,210)}=2.39$, $p=0.023$; VEH: context effect: $F_{(1,28)}=7.68, p=0.01$; day $\times$ context interaction: $F_{(7,196)}=7.23, p<0.0001$; TMX: context effect: $F_{(1,32)}=2.6, p=0.12$; day $\times$ context interaction: $F_{(7,224)}=$ $2.13, p=0.04$; Fig. $4 G$ ). By day 4 , control mice could efficiently discriminate between the contexts, while $i N R 2 B^{N e s}$ required $8 \mathrm{~d}$ to significantly discriminate between the contexts (day 4, repeated-measures ANOVA, treatment $\times$ context interaction: $F_{(1,30)}=5.6, p=0.02$; Fig. $\left.4 H\right)$.

\section{Discussion}

Adult hippocampal neurogenesis, a unique form of DG plasticity, is regulated by behavioral experience, and when manipulated can have specific effects on behavior. Recent hypotheses have suggested that the enhanced synaptic plasticity exhibited by 4 - to 6-week-old GCs allows them to uniquely contribute to hippocampal circuit function, and thus behavior, yet this has been difficult to test. Here we have examined the impact of this critical window of heightened plasticity on the function of young GCs. Deletion of the NR2B subunit from adult-born GCs resulted in an absence of ACSF-LTP similar to what is observed in neurogenesis ablation models, confirming that adult-born GCs are necessary for this form of plasticity via synaptic NR2B containing NMDA receptors. Surprisingly, unlike NR1 deletion (Tashiro et al., 2006), deletion of NR2B did not affect cell survival, possibly due of residual non-NR2B-containing NMDA receptors. Deletion of NR2B did reduce dendritic complexity, highlighting the differential role of NR2B in dendritic patterning of developmentally and adult-born GCs (Espinosa et al., 2009).

Lesion and genetic studies have documented a role for the DG in novelty exploration (Hunsaker et al., 2008). The DG may play a role in both novelty encoding and context discrimination by contributing to the extraction of novel features of an environment to facilitate the storage of similar experiences as distinct representations. $i N R 2 B^{N e s}$ mice showed a deficit in novelty exploration, which manifested as a decrease in novel object exploration. While arrest of adult neurogenesis has been shown to 
A

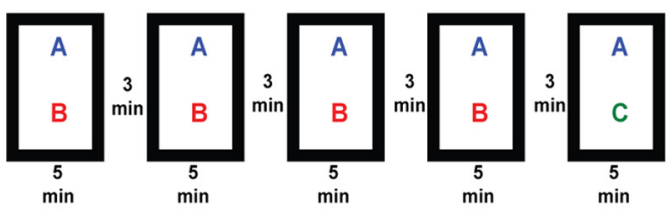

D $\quad \mathrm{TMX}$

$3 \mathrm{mg}$ IP

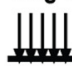

Day1-5

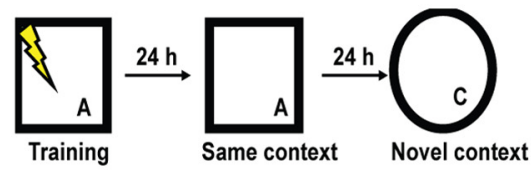

B

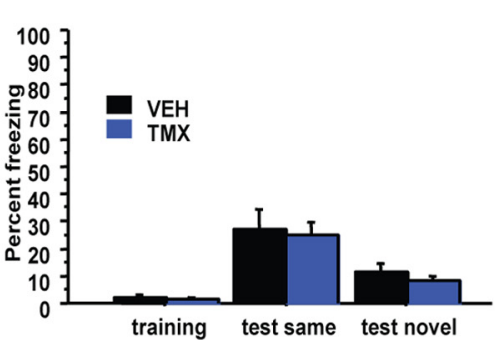

$\mathbf{F}$

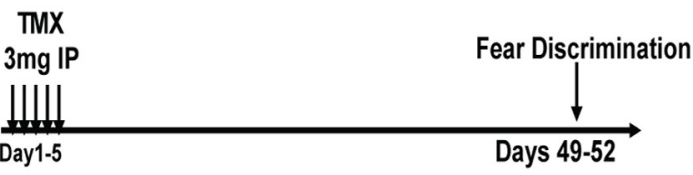

Day
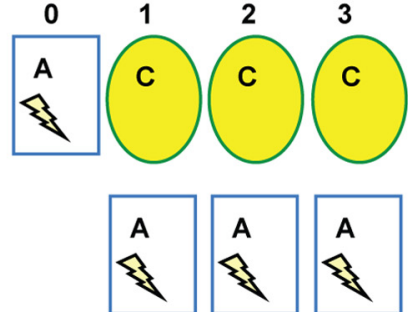

G

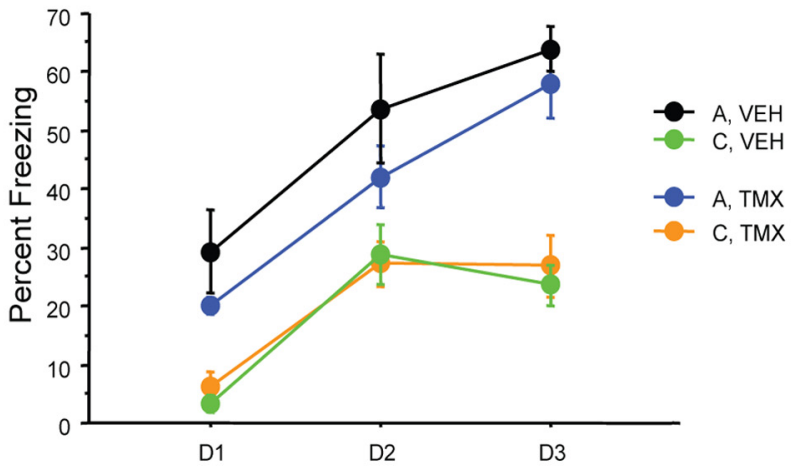

H

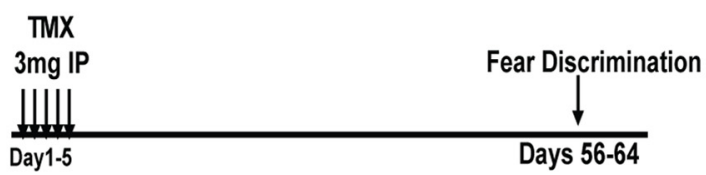

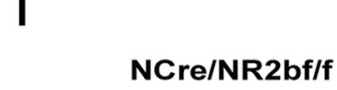

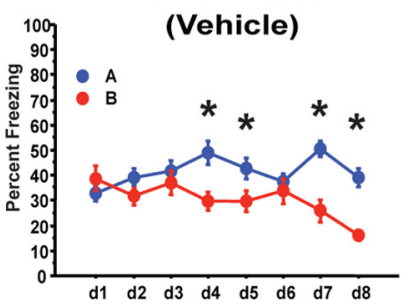

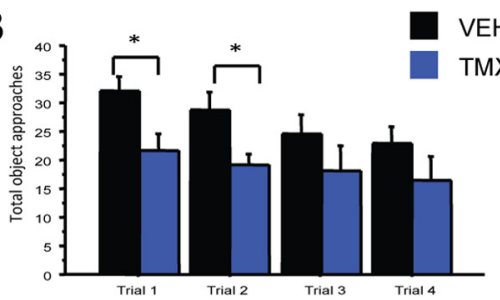

E

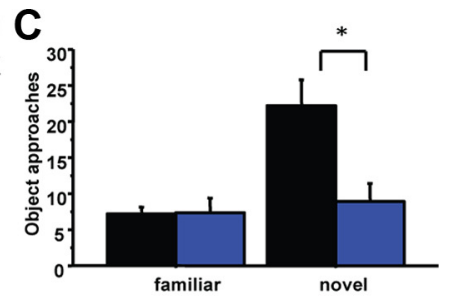

Fear Conditioning
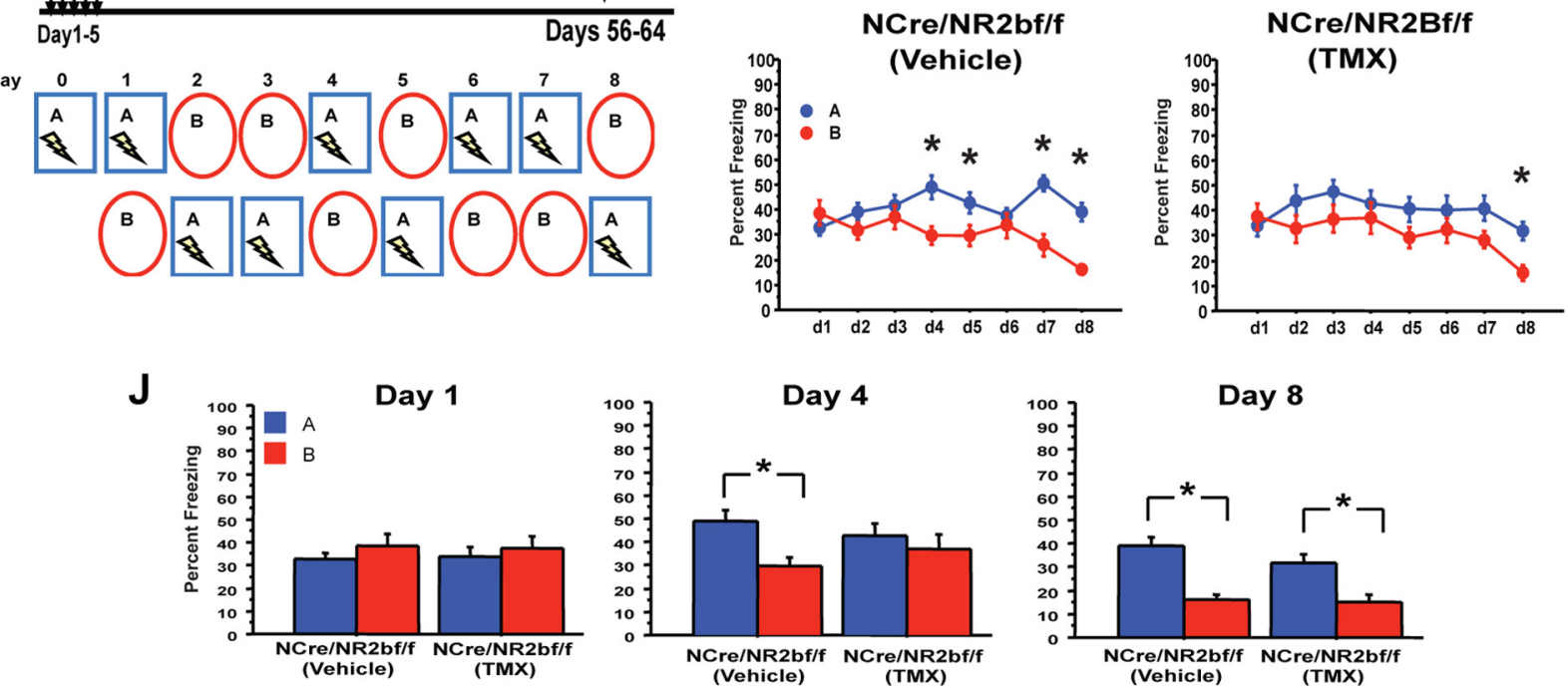

Figure 4. Impaired object exploration and contextual fear discrimination in $i N R 2 B^{\text {Nes }}$ mice. $A$, Experimental design for novelty exploration. $B, C$, Total approaches to the objects during training trials and testing reveal iNR2B $B^{\text {Nes }}$ mice explored the novel objects significantly less than control mice. $\boldsymbol{D}, \boldsymbol{E}$, iNR2B ${ }^{\text {Nes }}$ mice did not differ from controls in a one-shock contextual fear conditioning protocol, and did not generalize freezing to a novel context. $F, G, i N R 2 B^{\text {Nes }}$ mice did not differ from controls in discriminating between two different contexts (experimental design in $\boldsymbol{F}$ ). $\boldsymbol{H}, \boldsymbol{I}, i N R 2 B^{\text {Nes }}$ mice were slower to discriminate two similar contexts than VEH-treated controls (experimental design in $\boldsymbol{H}$ ). J, VEH-treated controls could discriminate by the fourth day of training, while iNR2 $B^{\text {Nes }}$ could not discriminate until the eighth day of training. ${ }^{*} p<0.05$. Data are mean \pm SEM. 
impact novelty recognition in mice (Denny et al., 2012) and rats (Jessberger et al., 2009), a number of studies have specified a role for the perirhinal cortex in object recognition memory (Winters and Bussey, 2005), suggesting that hippocampus may only play a role in object memory when contextual cues are used to support recognition (Winters et al., 2004). As $i N R 2 B^{N e s}$ mice were tested in the presence of extra-maze cues, this may have contributed to their decrease in novelty recognition. Alternatively, the decrease in object exploration during training may also have been responsible for their deficit in object recognition.

Multiple studies indicate that the DG, and specifically young GCs, play a role in pattern separation (Clelland et al., 2009; Sahay et al., 2011a; Nakashiba et al., 2012). Ablation of adult neurogenesis impairs appetitive spatial pattern separation as measured in a two-choice touch-screen task and a nonmatching to place radial arm maze task (Clelland et al., 2009). More recently, it has been shown that either increasing or decreasing levels of adult neurogenesis has bidirectional effects on the ability to distinguish between similar contextual representations in a fear discrimination task (Sahay et al., 2011a; Nakashiba et al., 2012). Here, we show that $i N R 2 B^{N e s}$ mice are impaired in this task, similar to what was found in irradiated mice (Sahay et al., 2011a; Nakashiba et al., 2012). These results suggest that the critical window of heightened plasticity of young neurons is necessary for their contribution to fine contextual discrimination. Thus, these studies indicate that the main contribution of adult-born neurons to hippocampal function occurs during their critical 4-6 week period of heightened plasticity and that this heightened plasticity modulates the DG/CA3 circuit to facilitate pattern separation.

\section{References}

Altman J, Das GD (1965) Autoradiographic and histological evidence of postnatal hippocampal neurogenesis in rats. J Comp Neurol 124: 319-335.

Clelland CD, Choi M, Romberg C, Clemenson GD Jr, Fragniere A, Tyers P, Jessberger S, Saksida LM, Barker RA, Gage FH, Bussey TJ (2009) A functional role for adult hippocampal neurogenesis in spatial pattern separation. Science 325:210-213.

Cull-Candy SG, Leszkiewicz DN (2004) Role of distinct NMDA receptor subtypes at central synapses. Sci STKE 2004:re16.

David DJ, Samuels BA, Rainer Q, Wang JW, Marsteller D, Mendez I, Drew M, Craig DA, Guiard BP, Guilloux JP, Artymyshyn RP, Gardier AM, Gerald C, Antonijevic IA, Leonardo ED, Hen R (2009) Neurogenesisdependent and -independent effects of fluoxetine in an animal model of anxiety/depression. Neuron 62:479-493.

Denny CA, Burghardt NS, Schachter DM, Hen R, Drew MR (2012) 4- to 6-week-old adult-born hippocampal neurons influence noveltyevoked exploration and contextual fear conditioning. Hippocampus 22:1188-1201.

Dranovsky A, Picchini AM, Moadel T, Sisti AC, Yamada A, Kimura S, Leonardo ED, Hen R (2011) Experience dictates stem cell fate in the adult hippocampus. Neuron 70:908-923.

Dulawa SC, Holick KA, Gundersen B, Hen R (2004) Effects of chronic fluoxetine in animal models of anxiety and depression. Neuropsychopharmacology 29:1321-1330.

Espinosa JS, Wheeler DG, Tsien RW, Luo L (2009) Uncoupling dendrite growth and patterning: single-cell knockout analysis of NMDA receptor 2B. Neuron 62:205-217.
Ge S, Goh EL, Sailor KA, Kitabatake Y, Ming GL, Song H (2006) GABA regulates synaptic integration of newly generated neurons in the adult brain. Nature 439:589-593.

Ge S, Yang CH, Hsu KS, Ming GL, Song H (2007) A critical period for enhanced synaptic plasticity in newly generated neurons of the adult brain. Neuron 54:559-566.

Hunsaker MR, Rosenberg JS, Kesner RP (2008) The role of the dentate gyrus, CA3a,b, and CA3c for detecting spatial and environmental novelty. Hippocampus 18:1064-1073.

Imayoshi I, Sakamoto M, Ohtsuka T, Takao K, Miyakawa T, Yamaguchi M, Mori K, Ikeda T, Itohara S, Kageyama R (2008) Roles of continuous neurogenesis in the structural and functional integrity of the adult forebrain. Nat Neurosci 11:1153-1161.

Jessberger S, Clark RE, Broadbent NJ, Clemenson GD Jr, Consiglio A, Lie DC, Squire LR, Gage FH (2009) Dentate gyrus-specific knockdown of adult neurogenesis impairs spatial and object recognition memory in adult rats. Learn Mem 16:147-154.

McNaughton BL (1980) Evidence for two physiologically distinct perforant pathways to the fascia dentata. Brain Res 199:1-19.

Nakashiba T, Cushman JD, Pelkey KA, Renaudineau S, Buhl DL, McHugh TJ, Rodriguez Barrera V, Chittajallu R, Iwamoto KS, McBain CJ, Fanselow MS, Tonegawa S (2012) Young dentate granule cells mediate pattern separation, whereas old granule cells facilitate pattern completion. Cell 149:188-201.

Sahay A, Scobie KN, Hill AS, O'Carroll CM, Kheirbek MA, Burghardt NS, Fenton AA, Dranovsky A, Hen R (2011a) Increasing adult hippocampal neurogenesis is sufficient to improve pattern separation. Nature 472:466-470.

Sahay A, Wilson DA, Hen R (2011b) Pattern separation: a common function for new neurons in hippocampus and olfactory bulb. Neuron 70:582-588.

Santarelli L, Saxe M, Gross C, Surget A, Battaglia F, Dulawa S, Weisstaub N, Lee J, Duman R, Arancio O, Belzung C, Hen R (2003) Requirement of hippocampal neurogenesis for the behavioral effects of antidepressants. Science 301:805-809.

Saxe MD, Battaglia F, Wang JW, Malleret G, David DJ, Monckton JE, Garcia AD, Sofroniew MV, Kandel ER, Santarelli L, Hen R, Drew MR (2006) Ablation of hippocampal neurogenesis impairs contextual fear conditioning and synaptic plasticity in the dentate gyrus. Proc Natl Acad Sci U S A 103:17501-17506.

Snyder JS, Kee N, Wojtowicz JM (2001) Effects of adult neurogenesis on synaptic plasticity in the rat dentate gyrus. J Neurophysiol 85:2423-2431.

Tashiro A, Sandler VM, Toni N, Zhao C, Gage FH (2006) NMDA-receptormediated, cell-specific integration of new neurons in adult dentate gyrus. Nature 442:929-933.

Toni N, Laplagne DA, Zhao C, Lombardi G, Ribak CE, Gage FH, Schinder AF (2008) Neurons born in the adult dentate gyrus form functional synapses with target cells. Nat Neurosci 11:901-907.

von Engelhardt J, Doganci B, Jensen V, Hvalby Ø, Göngrich C, Taylor A, Barkus C, Sanderson DJ, Rawlins JN, Seeburg PH, Bannerman DM, Monyer H (2008) Contribution of hippocampal and extra-hippocampal NR2Bcontaining NMDA receptors to performance on spatial learning tasks. Neuron 60:846-860.

Winters BD, Bussey TJ (2005) Transient inactivation of perirhinal cortex disrupts encoding, retrieval, and consolidation of object recognition memory. J Neurosci 25:52-61.

Winters BD, Forwood SE, Cowell RA, Saksida LM, Bussey TJ (2004) Double dissociation between the effects of peri-postrhinal cortex and hippocampal lesions on tests of object recognition and spatial memory: heterogeneity of function within the temporal lobe. J Neurosci 24:5901-5908.

Zhao C, Deng W, Gage FH (2008) Mechanisms and functional implications of adult neurogenesis. Cell 132:645-660. 